\title{
Construction and installation engineering for floating wind turbines
}

\author{
A.P. Crowle*, and $P R$ Thies \\ University of Exeter, College of Engineering, Mathematics and Physical Sciences \\ Renewable Energy Group, Penryn Campus, Treliever Road, TR10 9FE, UK
}

\begin{abstract}
The construction and installation engineering of floating offshore wind turbines is important to minimize schedules and costs. Floating offshore wind turbine substructures are an expanding sector within renewable power generation, offering an opportunity to deliver green energy, in new areas offshore. The floating nature of the substructures permits wind turbine placement in deep water locations. This paper investigates the construction and installation challenges for the various floating offshore wind types. It is concluded that priority areas for project management and design engineers minimising steel used in semi submersible construction, reducing the floating draft of Spars and for Tension Leg Platforms developing equipment for a safe installation.

Specifically tailored design for construction and installation includes expanding the weather window in which these floating substructures can be fabricated, transported to and from offshore site and making mooring and electrical connection operations simpler. The simplification of construction methodology will reduce time spent offshore and minimise risks to installation equipment and personnel. The paper will include the best practice for ease of towing for offshore installation and the possible return to port for maintenance. The construction and installation process for a floating offshore wind turbine varies with substructure type and this will be developed in more detail in the paper. Floating offshore wind structures require an international collaboration of shipyards, ports and construction vessels, though to good project management. It is concluded that return to port for maintenance is possible for semi submersibles and barges whereas for Spars and TLP updated equipment is required to carry out maintenance offshore. In order to facilitate the construction and to minimize costs, the main aspects have to be considered i.e., the required construction vessel types, the distance from fit-out port to site and the weather restrictions.
\end{abstract}

\section{Introduction}

Floating offshore wind turbines are being developed to produce renewable energy in water depths beyond about 65 metres. Options for floating offshore wind turbines are

\footnotetext{
* Corresponding author: ac1080@exeter.ac.uk
} 
complex structures and are described in section 2. The requirements and facilities for construction are described in section 3. Typical construction techniques are presented in section 4 and installation sequence is provided in section 5 .

\section{Structures}

\subsection{Size and complexity}

Due to the size and complexity of floating offshore wind structures, as well as the weather conditions in which they are deployed and installed, the actual construction translating the design into a physical reality requires very sophisticated planning, engineering, management, and verification. These construction activities are embodied under the overall term constructability. The four main types of floating offshore wind turbine are) are shown in figure 1 and are the barge, semi submersible, the Spar and the Tension Leg Platform (TLP) and are classed per ref [1], [9], [10] and [11].

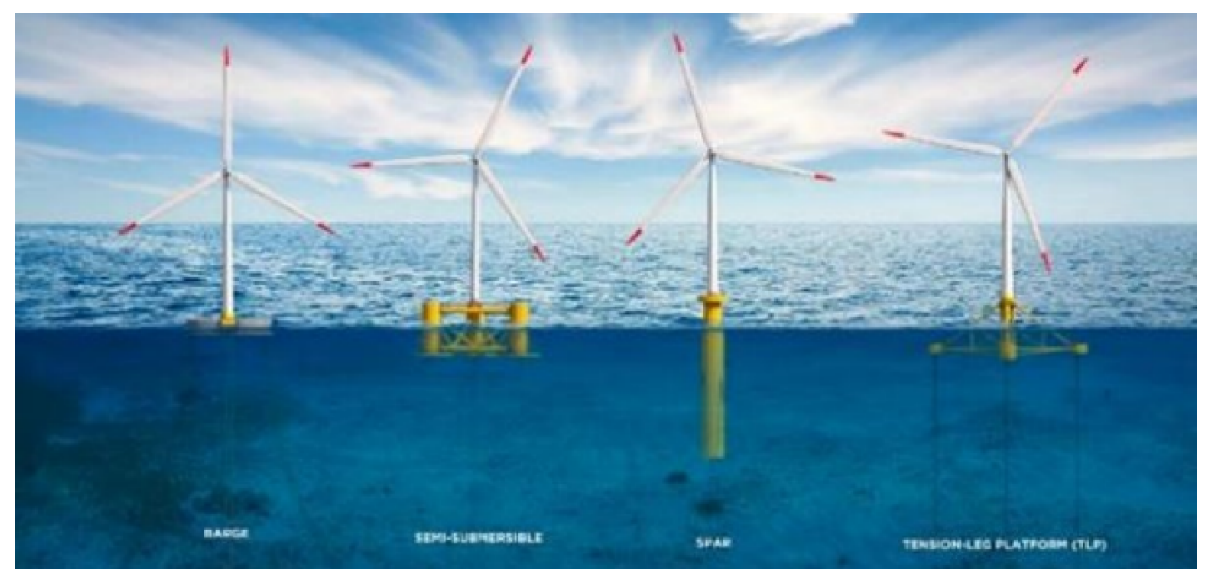

Fig. 1. Floating offshore wind turbine types (Ref [3]).

Floating offshore wind turbine (FOWT) structures and their associated subsea cables are very capital-intensive. They constitute a high early expenditure which increases the need to control construction costs. FOWT construction comprise thorough planning and competent project management.

The type of Floating offshore wind turbine determines the selection of construction methods, facilities and stages, the procurement and assembly of materials and fabricated components, the organization and supervision of the work, and the training of workers. During construction of the floating offshore wind turbine weight control is very important. Table 1 gives details of the constraints per type are presented.

Table 1. Construction restraints for FOWT.

\begin{tabular}{cccc} 
TLP & SPAR & BARGE & $\begin{array}{c}\text { SEMI } \\
\text { SUBMERSIBLE }\end{array}$ \\
\hline $\begin{array}{c}\text { Very Low intact stability, } \\
\text { ref [4] and [5] }\end{array}$ & $\begin{array}{c}\text { Needs solid ballast after } \\
\text { upending, ref [6] and [7) } \\
\text { Temporary buoyancy } \\
\text { needed offshore }\end{array}$ & $\begin{array}{c}\text { Long fit-out } \\
\text { quay length } \\
\text { inshore construction }\end{array}$ & $\begin{array}{c}\text { Long fit-out quay } \\
\text { length, ref [8] }\end{array}$ \\
Temporary buoyancy \\
in drydock
\end{tabular}


Requires specialised offshore crane vessel

Base for tendons needs offshore crane vessel
Deep water required for tow

to offshore site

Requires inshore crane vessel to install turbine

\subsection{Floating wind turbine components}

The main components of a floating offshore wind turbine are given in figure 2 . Constructability employs work simplifications and standardization techniques in order to overcome the difficulties inherent in complex and sophisticated construction in an offshore environment. Its scope includes construction, deployment and installation. Subsequent removal, towing ashore for maintenance, relocation, or salvage can also be considered as part of the constructability.

In constructability planning, it is essential to formally set these stages forth by title, description, and schematic drawing. Each of these major stages can then be subdivided into the detailed stages required. The stages should be further portrayed by a series of drawings or sketches. Isometric drawings to the structural capacity under differential heads, the intact stability performance afloat, and the instrumentation with its real-time readout are developed during the design and planning stage.
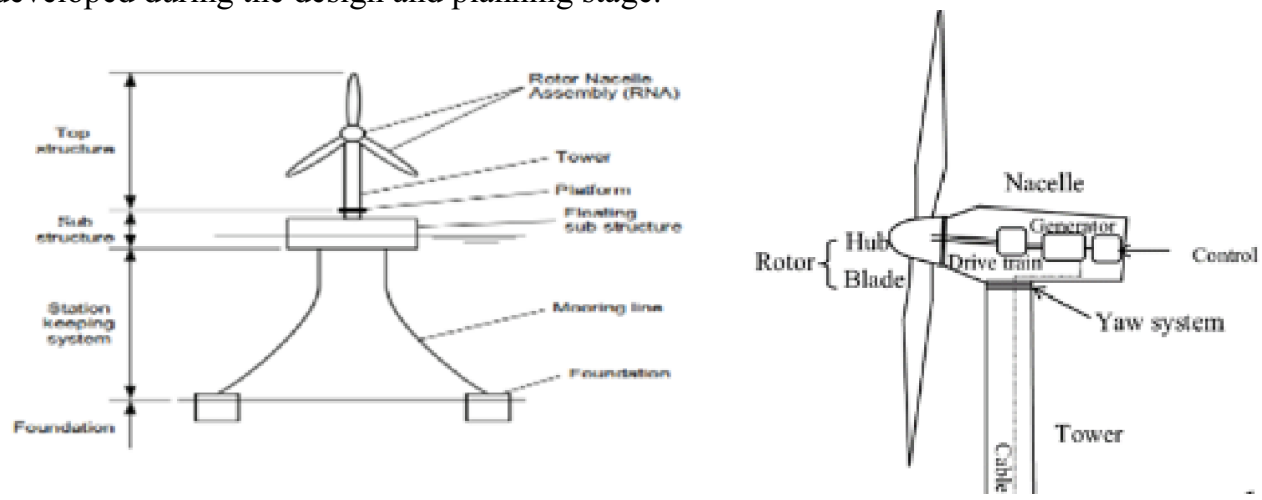

Fig. 2. Floating offshore wind turbine components (Ref [1]).

Engineering challenges are shown in Table 2 which compares construction and installation of floating offshore wind turbines (FOWT).

Table 2. Qualitative comparison of construction and installation FOWT options.

\begin{tabular}{ccccc} 
Item & TLP & SPAR & BARGE & $\begin{array}{c}\text { SEMI } \\
\text { SUBMERSIBLE }\end{array}$ \\
\hline Construction Land Area & Medium & Medium & Medium & Large \\
Ease of onshore construction & Medium & Medium & Medium & Medium \\
Seabed area & Low & Large & Large & Large \\
Intact stability in tow & Low & Large & Medium & Large \\
Attachment of moorings & Complicated & Standard & Standard & Standard \\
\hline
\end{tabular}




\section{Construction stages for floating offshore wind turbines}

A floating offshore wind turbine (FOWT) structure goes through a series of very distinct stages as it moves from construction to loadout (or float-out), to completion afloat, to transport, to installation, and to mooring connection and subsea hook-up.

Key considerations which have been inadequately addressed in the planning of previous structures include:

- Draft, with relation to available water depth during initial stages of construction afloat

- Intact stability during all stages of installation; including the effects of free surfaces

- Tie-down seafastenings of structures on heavy transport vessels

- Hydrodynamic response of structure during tow, especially acceleration forces

- Effect of pressure and temperature changes on function of instrumentation, valves

- Wave and current forces during construction and installation period.

- Effect of shallow water and minimal under-keel clearance

- Human error in ballasting control

- Inadequate weight and tolerance control during construction, leading to mishaps

- Vortex shedding, vibration and fatigue

- Welding temporary attachments and closures without following prescribed procedures

The division of the project into stages and the subdivision of each stage into actual steps is a procedure by which the most efficient method can be selected for each step. Sound judgment and experience will tend to integrate closely related steps within each stage. In floating offshore wind turbine construction, however, with its revolutionary developments in equipment, tools, and instrumentation, with its new structures and systems and environments, specific experience may not exist.

\section{Facilities and methods for construction}

\subsection{Design and procurement}

Design and procurement work is as follows:

- $\quad$ Seabed geotechnical surveys

- Design and procure materials

- $\quad$ Model Tests

- $\quad$ Set up substructure shipyard, ports for turbine fit-out, mooring laydown and cable laydown

\subsection{Early stages on shore}

For floating offshore wind turbine structures, the early stages of construction are carried out at a shore base. This base may be purpose-built for this one project or may be a relatively permanent facility. The area for such a facility must be adequate to accommodate not only the structure and/or components themselves but also storage of materials, access roads, support buildings, and infrastructure facilities.

Adequate roads must be constructed, e.g., of gravel, around the FOWT, and adequate drainage installed. The construction yard must be stable and firm enough to support the new FOWT substructure and the construction equipment. Since yards are located near the water, the original soils may require stabilization and fill such as compacted shell or crushed rock on which to operate. In weak sediments, filter fabric or pile supports may be required, over which rock may be placed, or a reinforced concrete slab. Particularly critical 
loadings occur with large crawler cranes, since when they pick their maximum loads, almost the full load of the crane itself plus the lifted load are concentrated on one crawler.

A number of methods have been developed to facilitate this movement from onshore to offshore. Some of these are briefly described below.

- Build on dry land and move onto a Heavy Transport Vessel, then travel to the fit-out port for FOWT float off, figure 3.

- $\quad$ Build in a dry dock and float the FOWT to the fit-out port, figure 4

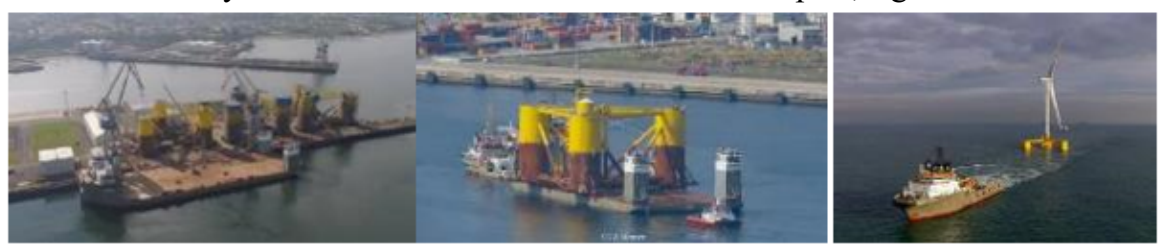

Fig. 3. Side loadout onto, tow to fit-out port, ocean tow complete FOWT(Ref [3]).
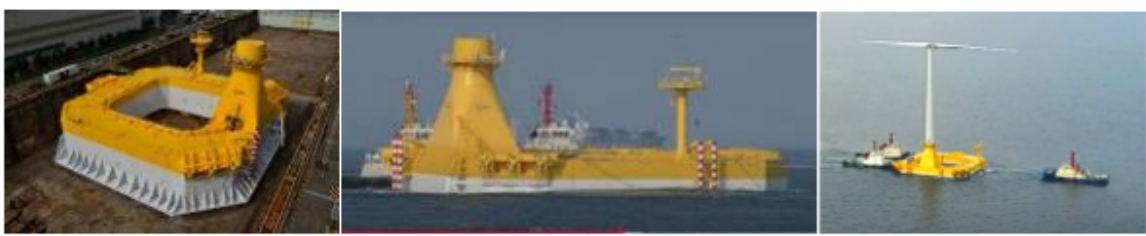

Fig. 4. Steel barge in dry dock and substructure tow and ocean towout (Ref [2]).

\section{Installation sequence}

\subsection{Early offshore activities}

Before towout of the FOWT the offshore moorings and inter array power cables are installed

\subsection{Offshore activities}

Offshore activities in sequence are:

- Tow complete Floating Offshore Wind Turbine to the offshore site

- Connect offshore moorings

- Connect offshore power cables

- Final commissioning

\section{Discussion and conclusions}

\subsection{Discussion}

The Spar has the advantage of low motions during the tow out, but has a deep draft of over $70 \mathrm{~m}$. The Semi submersible only requires shallow water (less than $10 \mathrm{~m}$ ) at the fit-out port, however it has a large substructure weight. The steel barge is simple to construct but requires many mooring lines. The TLP requires temporary buoyancy and a floating crane vessel for offshore installation. 
Engineering work for construction and installation includes:

- Naval Architecture = ballast, intact stability, ocean tow motions

- Structure engineers = strength for construction and installation

- Marine engineers = ballast piping

- Electrical engineers = subsea cable design

- Safety engineers $=$ transfer systems for personnel

\subsection{Conclusions}

There are several separate ports required for the construction and installation of floating offshore wind turbines:

- Shipyard for floating offshore wind turbine substructure construction (this is either on land or in a drydock)

- Laydown area for anchors (or mooring piles) and mooring lines

- Laydown area for the offshore power cables

- Fit-out port with laydown area for wind turbine components and space for a large crane.

Alan Crowle thanks his colleagues at the University of Exeter for their assistance in preparing this paper. Professor PR Thies would like to acknowledge the support through the EPSRC Supergen ORE Hub [EP/S000747/1].

\section{References}

1. DnV ules For Classification Floating Offshore Wind Turbine Installations, 2020

2. 'www.bw-ideol.com photos, 2020

3. 'www.principlepowerinc.com photos, 2020

4. 'www.bw.com photos, 2020

5. 'www.sbm.com photos, 2020

6. 'www.equinor.com photos, 2020

7. 'www.stiesdal.com photos, 2020

8. 'www.gustomsc.com photos, 2020

9. ABS Guide For Building And Classing Floating Offshore Wind Turbines, 2020

10. Bureau Veritas Classification and Certification of Floating Offshore Wind Turbines 2019

11. Class NK Guidelines for offshore floating wind turbine structures, 2012 